\title{
Abordagens participadas e coletivas da formação no contexto do poder local e na perspectiva do conhecimento como bem comum: um caso português
}

Rui Madeira ${ }^{1}$ - Pedro Ferrão ${ }^{2}$ - Artur Cristóvão ${ }^{3}$

\section{Resumo}

O Centro de Estudos Transdisciplinares para o Desenvolvimento - Vila Real, Portugal (CETRAD) e a Associação Nacional de Oficinas de Projetos (ANOP) desenvolveram, em 2007-2008, para a Associação de Municípios do Baixo Tâmega (AMBT), região do norte de Portugal, um estudo para uma nova abordagem do Diagnóstico de Necessidades de Formação e para uma aproximação a novos perfis profissionais ao nível dessa administração, contribuindo para a criação de sistemas de participação e cooperação em matéria de formação profissional. O estudo decorreu ao longo de um ano, com o envolvimento ativo de um conjunto de técnicos dos municípios, que serviram de "mediadores" entre as suas organizações e a equipa técnica do estudo. Em um processo de "bola de neve", muitos outros funcionários municipais participaram nas múltiplas atividades propostas, desde o exercício inicial de reflexão sobre os "clientes" das autarquias, aos workshops intermunicipais, a seminários temáticos, focus groups e no encontro outdoors de encerramento. Neste artigo, reflete-se sobre essa experiência e a possibilidade de desenvolver abordagens participadas e coletivas para a construção de Planos Diretores de Formação no quadro do poder local, em uma lógica intermunicipal. Apresentam-se a metodologia e os instrumentos utilizados e analisa-se criticamente o processo e a sua sustentabilidade no quadro do desenvolvimento organizacional e territorial.

Palavras-chave: Formação. Inovação. Municípios.

\section{Abstract}

The Center for the Development of Interdisciplinary Studies and the National Association of Projects, in 2007 - 2008, developed for the Association of Counties of

\footnotetext{
${ }^{1}$ Professor da Universidade de Trás-os-Montes e Alto Douro (UTAD) e pesquisador do Centro de Estudos Transdisciplinares para o Desenvolvimento(CETRAD) - Vila Real, Portugal.

${ }^{2}$ Professor da Universidade de Trás-os-Montes e Alto Douro (UTAD) e pesquisador do Centro de Estudos Transdisciplinares para o Desenvolvimento(CETRAD) - Vila Real, Portugal.

3 Professor da Universidade de Trás-os-Montes e Alto Douro (UTAD) e pesquisador do Centro de Estudos Transdisciplinares para o Desenvolvimento(CETRAD) - Vila Real, Portugal.
} 
the Lower Tamega River, a study for a new approach to the Diagnosis of the Formation Needs and for an approach to new professional patterns, contributing for the creation of participation and cooperation systems in terms of professional formation. The study was performed during one year with the active participation of the counties' technicians, who acted as "mediators" between their respective organizations and the technical group of the study. In a "snow ball" process, several municipal workers participated in the multiple activities, from the initial reflection exercise on the organizations' "clients", to the inter-counties workshops, to the thematic seminars, focus groups and last in the final seminar. In this paper we discuss this experience and the possibility of developing participative and collective approaches for the elaboration of Formation Master Plans (Planos Diretores de Formação) al local level, in an inter-county perspective. We present the methodology and the research instruments, and analyze critically the process and its sustainability in the perspective of the organizational and territorial development.

Keywords: Formation. Innovation. Counties.

\section{Introdução}

A falta de dinamismo e a burocratização da Administração Pública (AP), nomeadamente em nível local, tem vindo a ser identificado como um dos maiores problemas que afectam a sociedade portuguesa (CANÁRIO; CABRITO; AIRES, 2002). Com a imagem da AP a ser sucessivamente desgastada, aumenta a pressão, por parte dos destinatários das suas ações, do próprio governo, dos parceiros com quem trabalha e do ambiente geral em que opera, para que a AP altere o seu modo de funcionamento (NEVES, 2002), uma vez que será a partir dos desenvolvimentos que vão surgindo em nível da gestão pública, que, de acordo com Bravo e Sá (2000), será possível retirar os ensinamentos para aperfeiçoar o desempenho nas autarquias.

A modernização da Administração Pública Local em Portugal é hoje uma necessidade ainda mais premente no quadro da devolução de poderes do governo central para as autarquias locais, nomeadamente com o processo de descentralização que se tem vindo a verificar nos últimos anos e que se tem manifestado em novas competências e funções nas autarquias locais, no campo da saúde, do apoio social, da educação ou da formação, exigindo novas valências e colaboradores mais competentes, capazes de responder às novas solicitações que se colocam aos serviços (CABRITO, 2007).

Para Carapeto et al. (2006), qualquer solução que seja esboçada para a modernização da administração pública passa, desde logo, por um forte investimento nas pessoas, nomeadamente em nível das suas competências, do seu desenvolvimento pessoal e profissional, característica desejável, segundo Neves (2002), de um novo paradigma de gestão na AP. De fato, a formação tem sido entendida, à luz da teoria do capital humano - popularizada sobretudo por Theodore Schultz e Gary Becker -, como um investimento nesse tipo de capital que permite ganhos ao nível da produtividade. Apesar da "receita" parecer relativamente conhecida, a verdade é que os resultados das intervenções formativas não têm ido ao encontro daquilo que seria expectável. 
A problemática da formação e dos seus disfuncionamentos tem sido visível não só em nível da AP mas também em nível do próprio mundo empresarial. Caetano (1999) constata que, no nosso país, as organizações, em geral, levam a cabo ações de formação profissional focalizadas apenas nas suas necessidades atuais, ou seja, orientadas para um desenvolvimento pontual e eminentemente técnico, em uma perspectiva de curto prazo, sem um plano estratégico e sem critérios de eficácia e eficiência organizacionais, esgotando-se em si mesma, sem constituir uma mais valia para a organização.

Em um estudo de diagnóstico da situação da formação em nível das autarquias locais, levada a cabo por Canário, Cabrito e Aires (2002), os autores defendem que a formação padece de uma série de constrangimentos que ajudam a compreender a sua fraca eficácia e que poderão ser assim resumidos: ausência de uma "cultura de formação" que seja capaz de valorizar a formação e de torná-la uma prática estratégica dentro da gestão das autarquias locais (cultura de projeto); predominância de uma lógica de oferta da formação de tipo "catálogo" em vez de uma oferta mais preocupada em responder a problemas concretos, ou seja, concebida a partir de uma lógica de procura; exterioridade da oferta formativa, relativamente às pessoas e às organizações, orientada sobretudo para processos de qualificação individual; fortes assimetrias no acesso à formação, penalizando fortemente os grupos profissionais maioritários, menos qualificados, ao contrário dos segmentos hierarquicamente mais qualificados.

De acordo com Canário (2007), essas conclusões são congruentes com outros estudos de avaliação sobre programas de formação, quer a em nível da AP, quer em nível das autarquias locais, que apontam geralmente que a política de formação se apresenta como um "um fim em si mesma", sem ter em conta um projeto global para a organização, sendo os processos de construção da oferta formativa marcados pelo modelo burocrático e administrativo que prevalece no conjunto da organização.

Também Madeira (2004), com base em um estudo de caso levado a cabo em uma autarquia local, aponta que a política de formação se configura como tipicamente casuística, nascendo como que do acaso, obedecendo a sua lógica mais a critérios financeiros do que ao entendimento de que ela assume um papel estratégico relevante dentro do funcionamento da própria Câmara. Esse fato pode ser explicado pelo pouco envolvimento de todos aqueles que compõem o sistema cliente, nomeadamente por aqueles que têm mais responsabilidade: as chefias. Um plano de formação não emergindo de problemas detectados em situação de trabalho, próprio de uma organização que aprende, leva ao desinteresse por parte de todos aqueles que compõem o sistema cliente, que não entendem a sua pertinência.

Esse "quadro", aliás, já tinha sido apresentado, quase duas décadas antes, por Gaio et al. (1989), citados por Moreira (1995), quando fizeram o diagnóstico de como a formação tem sido entendida ao nível das autarquias locais:

- A formação profissional, na grande maioria das autarquias locais, é encarada como algo de subsidiário;

- Não existem políticas consistentes de formação profissional, sentidas e dinamizadas a partir de órgãos políticos responsáveis pela eficácia das instituições que dirigem; - É notória a tendência para respostas pontuais à oferta do mercado institucional, 
em que prevalece uma certa visão do aparelho administrativo regido por códigos e normativos, identificando a formação como um ato que educa simples executores de leis;

- A função formação, não obstante algumas experiências isoladas, dilui-se nas estruturas organizativas municipais, como simples tarefa de serviços administrativos absorvidos pela necessidade de cumprirem processos burocráticos, complexos e repetitivos;

- A formação raramente é utilizada como meio de motivação dos indivíduos e de prossecução de objectivos concretos das instituições.

Apesar de ser conhecido o "estado da arte" relativamente à formação, a verdade é que não temos conseguido ultrapassar aquilo que parece ser uma inevitabilidade: a falta de eficácia da formação.

No ano de 2000, foi criado o Programa Foral, para vigorar no período 2000-2005, mas, devido às dificuldades que se colocaram ao arranque do Programa, aquele período foi alargado até 2007. Trata-se de um programa financiado pelo Fundo Social Europeu, que tinha como objetivo apoiar a modernização da Administração Publica Local em Portugal, criando oportunidades de formação contínua dos funcionários das autarquias.

Apresentado como um projeto ambicioso, estratégico e com abrangência nacional, a verdade é que, nas palavras de Cabrito (2007, p. 431), a "análise dos dados disponíveis não indicia a introdução de melhorias na atividade de formação na Administração Pública Local que induzam a uma modernização efetiva da Administração em Portugal", levando a que "Portugal terá perdido, uma vez mais, uma oportunidade única para se modernizar e reforçar o processo de desenvolvimento necessário para 'apanhar' os seus parceiros comunitários".

A predominância - em mais de $92 \%$ do total das candidaturas - das chamadas "ações de formação", ações em sala de curta duração sem a participação ativa dos formandos na respectiva concepção, que não privilegia a partilha de experiências, nem a troca de informações, tampouco, em consequência, a mudança de comportamentos no sentido da inter-ajuda e da construção de uma cultura de projeto e de formação, parece contribuir, decisivamente, para esse desiderato - e isso apesar de se haver detectado novas metodologias de formação (em $8 \%$ dos casos), nomeadamente a formação - ação (CABRITO, 2007).

No rescaldo do Programa Foral, foi apresentado o relatório de um estudo de avaliação (NÓVOA; CABRITO; CANÁRIO, 2006), no qual são apresentadas algumas das conclusões e recomendações que sublinham a importância de modalidades de formação contextualizadas, em que as dimensões formais e não formais se combinam de modo fecundo (CANÁRIO, 2007). Aí são identificadas algumas modalidades de formação "portadoras de futuro" e dão exemplos de práticas apoiadas "numa relação fecunda entre a formação e os contextos de trabalho", bem como de práticas "baseadas em redes territoriais" que possibilitam otimizar recursos e promover a "articulação entre a formação e políticas integradas de intervenção" (WENGER; McDERMOTT; SNYDER, 2002, p. 74).

No sentido de melhorar a eficácia da formação, os autores recomendam a adoção de modalidades de trabalho pedagógico que permitam superar o caráter escolarizado que continua a dominar a oferta formativa profissional, com a predominância da chamada "ação de formação", isto é, ações que decorrem em sala, presenciais, obedecendo a uma lógica de transmissão de conhecimentos em uma relação entre professor/formador 
e formando do tipo emissor - receptor, dominada por uma relação de "dependência", reproduzindo o paradigma escolar (LOPES; RETO, 1994), podendo ser essa, no entender de Lopes (1999), uma das principais causas do descrédito em que a formação profissional se encontra no nosso país.

Assim, Nóvoa, Cabrito e Canário (2006) recomendam vivamente que projetos de formação visem a resolução de problemas concretos, e que possibilitem intervenções formativas de duração longa, integradas e integradoras, que incorporem mecanismos de regulação e de avaliação, prevendo e explicitando efeitos esperados ao nível organizacional. Esse tipo de formação implica a capacidade de utilizar e combinar uma diversidade de modalidades de trabalho pedagógico, construindo dispositivos de formação em que a dimensão da animação tem um papel estruturante e central.

Dessa forma, urge repensar toda a problemática da formação, para que essa "fatalidade" não se perpetue e se encontrem os caminhos que nos levem a retirar todas as potencialidades que a formação encerra. Assim parece que, apesar do reconhecimento generalizado do papel importante que a formação desempenha no nível da qualidade dos serviços que a administração pública oferece e, mais em particular, nas autarquias locais, os modelos que têm vindo a ser seguidos não respondem às necessidades e aos desafios que hoje se colocam a esse tipo de organizações.

Em meados de 2008, foi concluído um estudo, integrado no referido Programa FORAL, intitulado Elaboração Participada de Planos Directores de Formação e Identificação de Novas Competências na Administração Local dos Municípios do Baixo Tâmega, no qual participaram os autores no quadro de uma colaboração entre a Associação Nacional de Oficinas de Projeto (ANOP) e a UTAD. Esse estudo, cuja metodologia foi do tipo investigação-ação, durou cerca de um ano, envolveu os seis municípios do Baixo Tâmega e teve como objetivos:

(1) estabilizar um modelo de elaboração participada de planos diretores de formação; (2) identificar novas competências profissionais na administração local; (3) testar modelos instituídos de avaliação de competências no contexto específico da administração local; (4) experimentar estruturas de apoio consultivo e de envolvimento relacionadas com a formação; e (5) identificar novas figuras profissionais na administração local e definir o respectivo perfil de competências"(MADEIRA; FERRÃO; CRISTÓVÃO, 2008, p. 1-6).

Trata-se de um dos poucos projetos que, como referido, se distanciaram da abordagem mainstream efetivamente adotada naquele programa.

A participação dos autores neste estudo constituiu uma experiência rica, na medida em que o projeto, como se explica, confrontou a cultura tipicamente burocrática e hierarquizada da organização municipal com uma metodologia alternativa, de formação-ação, na linha das preocupações acima apresentadas, e a partir da qual se fez a reflexão que agora se apresenta, sendo a conclusão geral dupla: por um lado, confirmam-se e ilustram-se os problemas referidos e corroborados pela literatura mencionada e, por outro, procura-se precisar a problemática no sentido de orientar pesquisas subsequentes, sendo, aliás, objetivo dos autores revisitar o contexto em que teve lugar o estudo, a fim de avaliar os possíveis efeitos reais no médio prazo. 


\section{Modelo do Plano Diretor de Formação}

O Plano Director Intermunicipal de Formação (PDIF) é um dispositivo estratégico de formação de médio/longo prazo desenvolvido no quadro do estudo antes referido. Pretendeu-se fazer com que cada Câmara, suportada em uma lógica intermunicipal, assumisse o seu processo de formação. O Plano Diretor é, sobretudo, um instrumento de ação cultural que permite a reflexão conjunta, a criação de redes de solidariedade em redor de finalidades gerais de interesse comum, e pôr à disposição de todos um referencial partilhado quanto às prioridades, tornando-se mais um instrumento de gestão do que um instrumento de gestão operacional (MEIGNANT, 1999). Dessa forma, exprime uma vontade, uma visão e prioridades e traça linhas de força, não as traduzindo de forma operacional, mas antes refletindo sobre o desenvolvimento dos recursos humanos.

No contexto concreto das autarquias estudadas, o PDIF consistiu-se em:

- um conjunto de linhas orientadoras da formação;

- um modelo, complexo, de formação;

- uma série de exemplos de ações para satisfazer as necessidades detectadas ao longo do estudo.

\section{Referencial teórico do PDIF}

O PDIF tenta ser fiel a uma filosofia que entende a formação não como um fim em si mesmo, mas como um processo inacabado e contínuo em sucessiva reformulação e evolução, com o intuito de garantir uma eficaz gestão e desenvolvimento de competências. A formação de hoje insere-se em um contexto em que se desenvolvem as Organizações que Aprendem, no qual as situações formativas estão intimamente ligadas com as situações a resolver no momento, havendo uma ligação entre modos de aprendizagem e modos de organização do trabalho (MEIGNANT, 1999).

Esse tipo de formação, que indicia um processo de aprendizagem de forma ativa, aproxima-se da noção de action learning, vista como um mecanismo de aprendizagem, de formação ou como um processo de aprendizagem organizacional. Apesar de não haver uma simples definição, Zuber-Skerritt (2002) entende que é possível identificar algumas características do conceito: aprender fazendo; aprendizagem experiencial; refletir na prática; estar receptivo; partilhar ideias; colaboração; sinergias; aprender a aprender; aprendizagem ao longo da vida e aprendizagem no trabalho. Esse tipo de aprendizagem por meio da ação torna-se possível se a pessoa se transformar em um prático reflexivo, ou seja, alguém que dialoga com a situação e aprende.

O ponto essencial do modelo de Organização que Aprende consiste em que todos os colaboradores de uma organização se formem dentro de um contexto organizativo sistêmico e global, no qual a eficácia organizacional e a aprendizagem individual são consideradas fatores interdependentes. Os trabalhadores de uma cadeia de processos estarão em uma situação formativa se lhes forem dadas tarefas exigentes e receberem apoio para refletir continuamente sobre as mesmas, com o objetivo de aprender com elas. Dessa forma, o conteúdo do trabalho converte-se em um conteúdo formativo, e o 
trabalho e a formação/aprendizagem passam a formar parte de uma espiral de melhorias contínuas, exercendo um efeito quer no nível de competências técnicas dos trabaIhadores individuais, quer sobre a aprendizagem coletiva dos grupos de trabalho e sobre toda a organização.

A orientação da aprendizagem é de corresponsabilidade entre quem aprende e o próprio ambiente de trabalho. Enquanto que na organização especializante há clara distinção entre ação (trabalho) e aprendizagem, agora se entende que é na prática que se aprende e que a aprendizagem de novas competências influencia a atividade concreta da situação de trabalho. Isso vem colocar em causa, segundo Moura e Moura (2001), as formações clássicas escolarizadas dirigidas apenas à capacitação individual. Nesse momento, falamos em intervenções formativas que produzam mudanças no nível organizacional. De fato, no campo da formação profissional contínua, a tradicional dicotomia entre lugar de "aprender" e de "fazer", característico do modo escolar, é contrariada pela articulação entre práticas de formação contínua, orientadas, sobretudo, pelo indivíduo que aprende e pelo contexto de trabalho, ele também formativo, próprio de uma Organização que Aprende.

Assim, a aprendizagem vê-se fortalecida pela oferta de apoio e de feedback; pela tônica dada à reflexão; pela liberdade de experimentação própria e de resolução de problemas. Tal pode ser organizado por intermédio de reuniões de trabalho internas ou em grupos de avaliação de qualidade, nos quais os trabalhadores e os chefes discutem os problemas do dia a dia inerentes a uma tarefa, no intuito de resolvê-los e de introduzir melhoramentos.

$\mathrm{O}$ adulto aprendente deverá ser continuamente incentivado (tendo aqui as chefias um papel essencial) a colocar em prática as suas aprendizagens durante as situações de trabalho, em uma atmosfera organizacional na qual o erro e a experimentação a as sugestões propostas pelos colaboradores são entendidas como importantes instrumentos para a aquisição de competências. Esse envolvimento por parte de todo o sistema cliente, que traduz uma abordagem formativa centrada no cliente, leva a que esse sistema seja capaz de diagnosticar necessidades, e, em um processo negociado no seu interior, as prioridades e as modalidades de resposta a essas necessidades.

O conceito de competência é hoje central na formação e no trabalho, substituindo o de habilitação - conhecimento escolar - sendo de distinguir, como dimensões da competência, entre ter competência (saber-conhecimento, saber-fazer e saber-ser/estar) e ser competente (agir com competência) num contexto concreto; e, ainda, entre recursos, práticas e reflexividade. Quer isso dizer que uma pessoa, exercendo função numa organização, necessita, para lá do conhecimento técnico-científico, experiência na sua aplicação a problemas concretos de um dado contexto, capacidade de transferir para outros contextos e, ainda, capacidade de se integrar no coletivo da organização e de gerir adequadamente o seu relacionamento com os demais. Mais ainda: entendendo competência não como um estado mas como um processo integrado (LE BOTERF, 2006) envolvendo a pessoa, o seu grupo e o seu contexto, esse exercício das competências depende não só das qualidades e habilidades pessoais, da capacidade de as recontextualizar (reflexividade e transferibilidade), mas também de um contexto favorável à sua expressão (recursos e participação). Por outras palavras, de nada serve ter competências se a organização, 
para além da pessoa, não for capaz de mobilizá-las.

\section{Estratégia do PDIF}

O principal objectivo do PDIF foi garantir que, de uma forma sustentada (de meIhoria contínua), as $\mathrm{CM}$ e os seus colaboradores pudessem melhorar as suas competências (desenvolvimento organizacional e dos indivíduos enquanto pessoas), elevando a qualidade dos serviços prestados aos clientes, quer internos quer externos, na busca da excelência.

O PDIF traçado apontava para que cada CM evoluísse no sentido de uma Organização que Aprende, isto é, incrementasse a sua capacidade de autoformação, tomasse as situações de trabalho como oportunidades formativas e tornasse cada colaborador um prosumidor (produtor e consumidor) de conhecimento. Por outro lado, propunha os fundamentos para uma verdadeira cooperação Intermunicipal no nível da formação e formas de garantir a sua sustentabilidade (Comunidade Baixo Tâmega - fator Identidade) a partir da criação de mecanismos e de processos que levassem as CM a se tornarem, no seu conjunto, uma Comunidade Aprendente, em que as CM fossem parceiras, sob uma lógica colaborativa, de produção e gestão coletiva de conhecimento.

Esses objetivos, à luz do referencial teórico adotado, suscitam as seguintes questões, às quais o PDIF procurou responder:

Qual a estratégia de alcance da formação, isto é, deve a formação dirigir-se apenas aos conhecimentos técnicos ou deve abranger todas as dimensões da competência e, simultaneamente, as condições organizacionais para a sua expressão?

Qual o modelo de formação, isto é, deve a formação ser adquirida por processos de formação tradicional em sala ou deve antes basear-se num processo contínuo de formação - ação no contexto de trabalho e acompanhando os processos da organização?

Quais os processos e dispositivos de formação, isto é, quais esquemas e formas de interação e acesso ao conhecimento melhor correspondem à estratégia e modelo de formação e ao contexto concreto, cultural e técnico das autarquias locais? Qual é o ritmo cíclico mais adequado de funcionamento desses dispositivos?

Como deve ser monitorizada e avaliada a formação, isto é, como devem ser definidos os objetivos e indicadores da formação e verificados e apreciados pelos interessados?

No caso das autarquias do Baixo Tâmega, o estudo efetuado permitiu responder, com exemplos, às quatro questões colocadas. Desse modo, foi possível prosseguir, a partir desse estudo, com as seguintes iniciativas: a) melhorar e completar o PDIF a partir da experiência adquiridas; b) desenhar planos e dispositivos operacionais de formação; e c) dar início a ações e dispositivos concretos de formação relativos aos casos tratados.

Modelo de intervenção e suas estruturas

O modelo de intervenção pretendeu responder às questões estratégicas colocadas. 
O PDIF assentou, como foi referido, na ideia de que a formação deve ser um processo a ser apropriado pelas próprias CM por meio dos seus colaboradores. Isso significa que a formação deve seguir uma lógica baseada na procura e não na oferta de planos de formação.

Para que o PDIF fosse desenvolvido e colocado em prática, foi necessária uma aposta importante, em nível político, nas estruturas que o suportam, nomeadamente os Focus Group, a Comunidade Intermunicipal de Animadores e a Comunidade Intermunicipal de Área, que devem funcionar em pleno, com legitimidade, quer internamente, quer no nível intermunicipal.

Os setores e departamentos das CM foram agrupados em quatro áreas, ultrapassando as diferenças dos respectivos organogramas e juntando setores afins: 1) Desenvolvimento Municipal; 2) Administração Geral, Finanças e Assuntos Jurídicos; 3) Urbanismo e Planeamento; 4) Obras. Chefias e quadros técnicos das quatro áreas definidas participaram em outras tantas comunidades de prática, isto é, juntaram-se em encontros intermunicipais regulares para discutir os assuntos próprios de cada área. Por outro lado, participaram também em um Focus Group da própria CM, que se reuniu regularmente para discutir problemas transversais, isto é, comuns a vários departamentos autárquicos, conforme llustração 1.

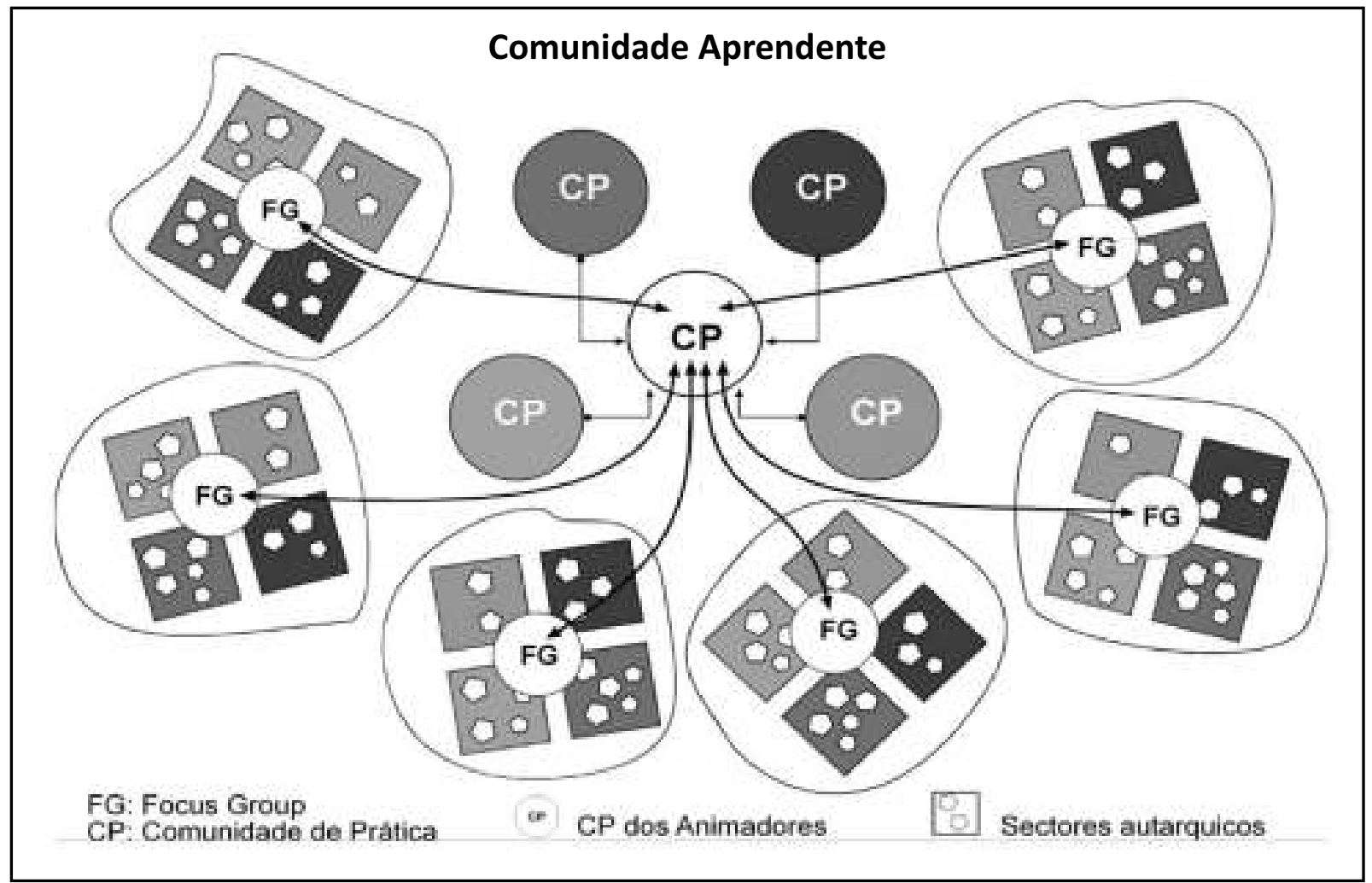

Ilustração 1 - Estruturas da comunidade aprendente Fonte: autores

A animação foi efetuada por um ou mais animadores de cada CM, que dinamizaram o FG respectivo e igualmente se encontraram de forma regular, formando uma comunidade de prática de animadores, na qual foi debatida a animação interna e intermunicipal. 
Em suma, e pormenorizando, as estruturas centrais do modelo ensaiado no estudo foram as seguintes:

Animador: pessoa designada para promover a colaboração subjacente ao PDIF e suprir a falta de um responsável direto pela área de desenvolvimento, quer das competências pessoais, quer coletivas, dentro das CM. A missão do animador é garantir que a formação seja um processo contínuo, colaborativo e participado, promovendo uma atmosfera de melhoria contínua.

Focus Groups: reúnem pessoas com diferentes especialidades, mas com problemas comuns - lógica transversal intramunicipal. Cada CM deve manter um FG que funcionará com elementos, preferencialmente até 10 participantes, representativos de todas as seções/setores/departamentos, nomeadamente no nível das chefias e quadros técnicos.

Comunidade de Animadores: comunidade de prática da qual fazem parte os animadores de cada CM. Por comunidade de prática, entende-se um grupo auto-organizado de pessoas que partilham a paixão por uma atividade e interagem regularmente para troca de conhecimento sobre a prática dessa atividade (WENGER; McDERMOTT; SNYDER, 2002). No caso da comunidade de animadores, a prática partilhada diz respeito à animação da comunicação e dos processos formativos intermunicipais.

Comunidades Intermunicipais de Área: são comunidades de prática das quais fazem parte chefias e quadros técnicos de especialidades idênticas (mesma área), mas com problemas comuns, pertencentes a diferentes autarquias.

Embora concebido para os seis municípios do Baixo Tâmega e experimentado em cinco deles, o modelo pode ser aplicado a um maior número de $\mathrm{CM}$, possivelmente no quadro de uma articulação regional mais alargada. É importante sublinhar que as estruturas que se indicam têm um caráter informal e eminentemente consultivo, não pondo em causa as estruturas hierárquicas e de responsabilidade da organização.

Essas estruturas devem articular-se em uma lógica interdependente, ou seja, para que se consigam os melhores resultados, todas as estruturas devem funcionar com base numa grande "cumplicidade" e de forma solidária, em que todos dependem de todos e, por outro lado, de forma sistémica: sendo um processo em constante reformulação e avaliação, o seu funcionamento ajuda-o a fortalecer.

A llustração 2 pretende mostrar o conjunto do modelo proposto e experimentado. 


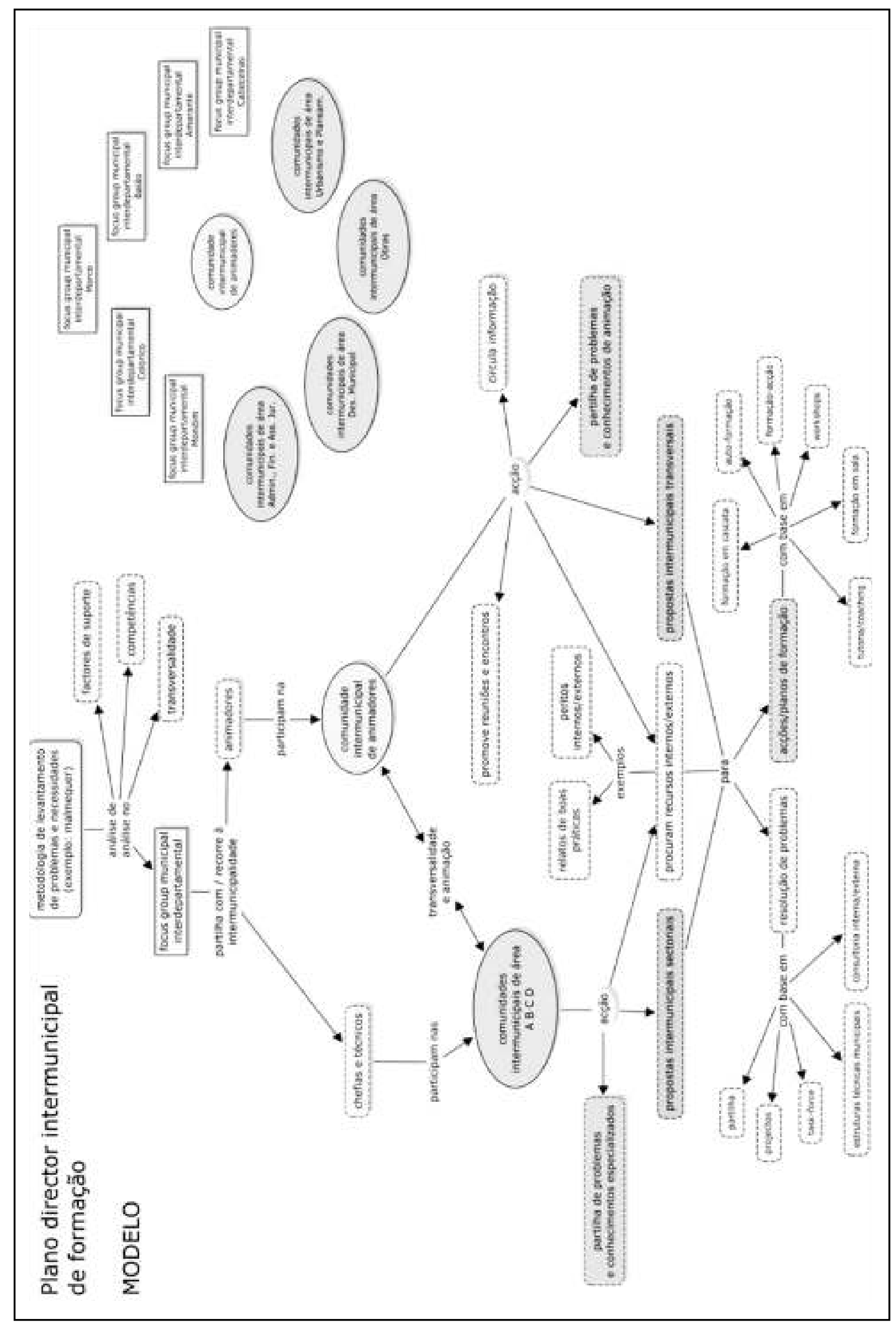

Ilustração 2 - Modelo do PDIF

Fonte: autores 


\section{Perspectiva dos participantes}

Os pontos essenciais da visão dos participantes aqui coligidos resultam de uma leitura seletiva e transversal das nove narrativas pessoais recolhidas na fase final do projeto, e das quais se apresentam excertos com o objectivo de apreender a dinâmica do processo e elaborar algumas linhas de interrogação.

Inovação e mudança organizacional

Os participantes apreenderam o objetivo de introdução, na cultura fortemente hierárquica dessas instituições, de uma perspectiva de partilha horizontal de conhecimento, quer inter, quer intramunicipal, bem como o valor e a naturalidade dessa partilha quando tornada possível.

Cooperação e transversalidade intramunicipal

A cooperação e a transversalidade intramunicipal do projeto pode ser verificada a partir de comentários de participantes do projeto inseridos no relatório final, como: “[...] projeto importante para a Câmara onde trabalho [...] pela possibilidade de [...] integrar as várias unidades orgânicas da Câmara num mesmo projeto e num mesmo espaço de reflexão" (CM de MB, relatório do projeto [1-3.55]) e que "permitiu [...] comprovar que se alcançam resultados muito mais profícuos do que quando se trabalha individualmente" (CM de MB, relatório do projeto [1-3.56]) . "A discussão era nova para a maior parte dos colaboradores" (CM de MB, relatório do projeto [1-3.54]), a propósito da fase inicial do projeto e da utilização da perspectiva do cliente.

Cooperação inter-organizacional

Refere-se que "não há sistemas de comunicação intermunicipais instalados" mas que os encontros intermunicipais no âmbito do estudo permitiram "juntar elementos dos diferentes municípios com experiências similares, desafios comuns e realidades organizacionais semelhantes" pelo que "os municípios deviam comunicar mais entre si, potenciando sinergias e rentabilizando experiências" (CM de B, relatório do projeto [13.57]). "Encontros como estes deveriam ser repetidos: servem como divertimento, mas também como meio de conhecimento, contato e troca de experiências entre municípios" (CM de A, relatório do projeto [1-3.59]), uma vez que "foi um tempo de reunião e partilha de ideias que por vezes podem ser tão ou mais profícuos que outros momentos de transmissão de informação ou de formação mais formais. [...] Aprendi e (re)aprendi que é possível desenvolver as teias intermunicipais - principalmente dentro de serviços ${ }^{1}$ Conforme citação do relatóriodo referido projeto, por "CM de $\mathrm{MB}^{\circ}$ entende-se como comentário de um participante do
projeto, representado apenas pelas iniciais do(s) seu(s) primeiro(s) nome(s), neste caso, "MB". 
semelhantes - e, igualmente produtivo, intramunicipais - principalmente entre serviços diferentes. As atividades de grupo podem ser um facilitador para o desenvolvimento dessas redes que, por sua vez, aproximam as pessoas, diminuem os tempos de resolução de tarefas e identificam e permitem partilhar e adoptar informações e métodos de trabalho mais adequados e eficazes" (CM de CB, relatório do projeto [1-3.59]).

Inovação no processo

A metodologia do estudo, do tipo investigação-ação, permitiu que, além do diagnóstico de necessidades de formação propriamente dito, os participantes experienciassem, quer a metodologia de diagnóstico quer algumas formas de formação-ação alternativas à ação formativa tradicional, o que se traduziu em uma compreensão ao mesmo tempo mais abrangente e mais intuitiva das propostas metodológicas do estudo, nomeadamente em termos do paradigma de formação. Este fato é confirmado pelo elevado número de referências à inovação no plano processual.

"Aprendi a olhar a formação sob uma perspectiva diferente, [...] agora reconheço que a formação deve ser encarada num quadro de mudança em que a entidade se reveja e ser feita de variadíssimas formas [...]. Tratou-se de um processo inovador de levantamento de necessidades de formação que conseguiu levar as pessoas a pensar nos problemas em sentido lato" (CM de MB, relatório do projeto [1-3.56]).

O processo envolveu uma "metodologia que inova em termos das tradicionalmente aplicadas nas Câmaras, pelos funcionários e chefias. Permitiu a reflexão/discussão conjunta de problemas e a consciencialização sobre a sua existência. Significou, ainda, que uma solução/sugestão para um pode constituir um problema para outro. Permitiu, também, o reconhecimento dos aspectos positivos dos serviços e da comunicação interna. É uma metodologia trabalhosa, demorada, no sentido de que pressupõe mudança de atitudes e que, por isso, pressupõe um maior acompanhamento técnico inicial no local. Os resultados são participados", originando "dentro dos diagnósticos realizados no município, um levantamento mais real e fidedigno. A dificuldade e arte estão em dar-Ihes seguimento". Igualmente, "identifica os aspectos positivos que, muitas vezes, são relegados para segundo ou terceiro plano" (CM de CB, relatório do projeto [1-3.60]). Os encontros "mostraram [...] que é em ambiente parcialmente informal, no encontro com colegas, que encontramos soluções para os problemas diários com que nos confrontamos no dia a dia [...] e sermos 'professores' e 'consultores' uns dos outros (CM de CB, relatório do projeto [1-3.61]). "Tratou-se de uma experiência de trabalho única, na qual todos os envolvidos puderam, pela primeira vez, interagir, trocar impressões, reflectir e (até) rir em conjunto" (CM de MC, relatório do projeto [1-3.63]).

Motivação e participação

Do ponto de vista da motivação, "a forma encontrada pela equipa para dinamizar o processo [...] mostrou que é possível e encorajador trabalharem-se assuntos sérios 
com ferramentas e práticas descontraídas. Desafiam a imaginação das pessoas, suscitam interesse suplementar e superam a motivação habitual" (CM de MB, relatório do projeto [1-3.56]). Os participantes nos focus group sentiram ter "um papel reflexivo importante no planeamento estratégico da formação", sendo relevante a "oportunidade dada a colaboradores de partilhar e de expressar opiniões e visões acerca da organização, bem como a possibilidade de concertar estratégias para a organização" (CM de B, relatório do projeto [1-3.56]).

\section{Dificuldades e limitações}

Investimento temporal

O estudo, pela sua novidade e pelos processos abertos introduzidos, impôs a necessidade de socializar metodologias, articular expectativas de diferentes graus e orientações, compatibilizar agendas e partilhar reportórios conceptuais e linguagens, o que se traduziu num importante investimento de tempo: "a criação de tempo suplementar para dinamizar grupos de debate nas Câmaras Municipais pode ser um dos desafios" (CM de CB, relatório do projeto [1-3.61]).

Reflexividade

Os participantes refereriram a dificuldade em traduzir as preocupações detectadas em propostas de formação que não sejam orientadas para aspectos meramente operativos, na linha do que foi referido na introdução: "incapacidade para identificarmos necessidades de formação/ação" sendo apenas "identificadas necessidades de formação técnica", mas "perdendo-se, em parte, a visão da instituição" (CM de MB, relatório do projeto [1-3.56]).

Estrutura hierárquica e burocrática

Por um lado, registaram a dificuldade de envolver os dirigentes máximos da autarquia (o "executivo"): "[...] era necessário ir fazendo o ponto de situação ao executivo [...]. Explicar a metodologia [...] que se tratava de uma 'nova forma' de participação, não em uso na entidade, mas que deveria ser entendida como uma participação construtiva para a melhoria dos serviços de cada secção, e não de outra forma" (CM de MB, relatório do projeto [1-3.54]). Por outro lado, o fator favorável do envolvimento da chefia intermédia: "envolvência, esclarecimento, comunicação, interesse da chefia são palavras-chave para o sucesso" (CM de MB, relatório do projeto [1-3.55]).

A propósito dos encontros intermunicipais, "Este espírito forte, combativo e até competitivo, de unir esforços para superarem limitações individuais parece, por vezes, estar ausente da função pública mas foi, no entanto, visivelmente manifestado nessa manhã" (CM de B, relatório do projeto [1-3.60]). 


\section{Conclusões}

O modelo de formação descrito enquadra-se em um paradigma de formação-ação que, como se viu, se situa fora da abordagem mainstream da formação no contexto autárquico. Os testemunhos obtidos mostram obstáculos e virtudes inerentes a essa abordagem. Do lado das virtudes já referidas, são de salientar: a adequação às reais necessidades de conhecimento, sob uma perspectiva dinâmica e sistémica, o controle do processo pelos sujeitos envolvidos e o desenvolvimento de práticas e culturas de trabalho em rede. Do lado dos obstáculos, destacam-se: o investimento temporal requerido, todavia compensado pelos baixos custos de aquisição de serviços, a necessidade de apoio especializado para a dinamização do processo e da tradução dos diagnósticos em ações práticas e ainda a falta de sensibilidade e apoio por parte do topo das hierarquias, por vezes traduzidos em uma separação entre as lideranças técnicas e as lideranças políticas.

O estudo sugere que as autarquias, que têm já experiência de gestão comum em outros domínios mais tangíveis, como é o caso dos resíduos sólidos e da água, ainda não encaram o conhecimento como um recurso partilhável em uma perspectiva do knowledge as a commons, fato tanto mais relevante quanto o conhecimento não é um "recurso substrativo" (HESS; OSTROM, 2007).

Outro problema que pode ser encontrado no estudo é o da transição de estruturas e culturas organizacionais, ou da inovação organizacional, no contexto das autarquias. Pode dizer-se que esse tipo de projeto é ainda uma "novidade", no sentido de que constituiu uma quebra localizada na rotina do paradigma dominante da organização e da gestão do conhecimento nas autarquias, e que, para se generalizar, teria ainda de constituir "nichos", isto é, redes sociotécnicas de experimentação e de partilha de conhecimento tácito (capital social) antes de se converter em "regime" e, finalmente, em "paisagem" dominante, segundo Brunori et al. (2008). Essa será, porventura, uma linha de pesquisa prioritária para a compreensão dos obstáculos a enfrentar, nas organizações autárquicas, na adoção do conhecimento como bem comum.

\section{Referências}

BRAVO, A. B.; SÁ, J. V. Autarquias Locais - Descentralização e Melhor Gestão. Lisboa; São Paulo: Verbo, 2000.

BRUNORI, G. et al. Towards a conceptual framework for agricultural and rural innovation policies. Report on the project "Strengthening Innovation Processes for Growth and Development (IN-SIGHT)", funded by the 6th Framework programme of the European Union, 2008.

CABRITO, B. G. El Programa Foral y la Formación Profesional en la Administración Local, en Portugal. In: Investigaciones de Economia de la Educación. QUINTANA, C. D. et al. XVI Jornadas de la Asociación de Economía de la Educación. Gran Canaria: Asociación de Economía de la Educación y Delta Publicaciones, 2007. p. 421-431. 
CAETANO, A. Mudança organizacional e gestão de recursos humanos. Lisboa:

Observatório do Emprego e Formação Profissional, 1999.

CANÁRIO, R. Aprender sem ser ensinado. A importância estratégica da educação não formal. In: AAVV, A Educação em Portugal (1986-2006). Alguns contributos de investigação. Lisboa: Conselho Nacional de Educação, 2007. p. 207-267.

CANÁRIO, R.; CABRITO, B.; Aires, R. Formação profissional contínua na administração local: para uma orientação estratégica. Lisboa: FPCE, 2002.

CARAPETO, C. et al. Administração Pública - Modernização, Qualidade e Inovação. 2. ed. Lisboa: Sílabo, 2006.

HESS, C.; OSTROM, E. Understanding Knowledge as a Commons. Cambridge; London: MIT Press, 2007.

LE BOTERF, Guy. Construire les Compétences Individuelles et Collectives. 4. ed. Paris: Eyrolles - Editions d'Organisation, 2006.

LOPES, A. Eficácia económica e eficácia social - o duplo desafio da formação profissional contínua e a medição dos seus resultados. In: Comissão Coordenação do Fundo Social Europeu. CCFSE (Ed.). Formação para as PME, Bruxelas, 1999.

LOPES, A.; RETO, L. Formação Profissional. Avaliação da eficácia e metáforas dominantes, Psicologia, Lisboa, ano IX, n. 3: p. 307-313. 1994.

MADEIRA, R. A. Avaliação da Formação: o caso das Autarquias Locais. (Mestrado) - Instituto Superior das Ciências do Trabalho e da Empresa, Lisboa, 2004.

MADEIRA, R.; FERRÃO, P.; CRISTÓVÃO, A. Elaboração Participada de Planos Directores de Formação e Identificação de Novas Competências na Administração Local - Baixo Tâmega. Associação dos Municípios do Baixo Tâmega, 2008.

MEIGNANT, A. A Gestão da Formação. Lisboa: Dom Quixote, 1999.

MOREIRA, R. A função formação nas autarquias locais. Ministério do Planeamento e Administração do Território. Lisboa: CCRN, 1995.

MOURA, R.; MOURA, K. Referencial de evolução das empresas. In: MOURA, R. (Coord.). Evolução das políticas de formação nas empresas. Lisboa: Observatório do Emprego e Formação Profissional, 2001.

NEVES, A. Gestão na Administração Pública. Lisboa: Pergaminho, 2002.

NÓVOA, A.; CABRITO, B.; CANÁRIO, R. Estudo nacional de avaliação de impactos da formação realizada para a administração local no âmbito do Programa Foral. Lisboa: Universidade de Lisboa, 2006.

WENGER, E.; McDERMOTT, R.; SNYDER, W. Cultivating Communities of Practice. Boston: Harvard Business School Press, 2002.

ZUBER-SKERRITT, O. The Concept of Action Learning. The Learning Organization, v. 9, n. 3, p.114-124. 2002. 